\title{
Is prenatal arsenic exposure associated with salivary cortisol in infants in Arica, Chile? An exploratory cohort study
}

\author{
Macarena Valdés Salgado ${ }^{1, A-D, F}{ }^{\oplus}$, Enrique Schisterman ${ }^{2, C, E-F}{ }^{\circ}$, Paulina Pino ${ }^{1, C-F}{ }^{\oplus}$, \\ Shrikant Bangdiwala ${ }^{3, C, E-F}$, María Pía Muñoz ${ }^{1, B, E-F} \oplus$, Verónica Iglesias ${ }^{1, A-C, E-F} \oplus$ \\ ${ }^{1}$ School of Public Health, Faculty of Medicine, University of Chile, Santiego, Chile \\ ${ }^{2}$ Epidemiology Branch, Eunice Kennedy Shriver National Institute of Child Health and Human Development, Rockvill \\ $(M D)$, United States \\ ${ }^{3}$ Population Health Research Institute. McMaster University, Hamilton, Ontario, Canada \\ A - Research concept and design, B - Collection and/or assembly of data, C - Data analysis and interpretation, \\ $D$ - Writing the article, $E$ - Critical revision of the article, $F$ - Final approval of article
}

\begin{abstract}
Valdés Salgado M, Schisterman E, Pino P, Bangdiwala S, Pía Muñoz M, Iglesias V. Is prenatal arsenic exposure associated with salivary cortisol
\end{abstract} in infants in Arica, Chile? An exploratory cohort study. Ann Agric Environ Med. 2019; 26(2): 266-272. doi: 10.26444/aaem/104586

\begin{abstract}
Introduction. In animal models, gestational exposure to inorganic arsenic has been associated with higher corticosterone concentration and consequent impairment of stress control in offspring. An equivalent association relating cortisol, a glucocorticoid hormone, in humans has not been previously studied.

Objective. The aim of the study was to explore the association between prenatal inorganic arsenic exposure and salivary cortisol in infants from Arica, Chile.

Materials and method. A cohort study of 168 mother-child dyads was recruited. In the 2nd trimester of pregnancy, urinary inorganic arsenic was assessed; 18-24 months after delivery, salivary cortisol was measured in the children. Maternal cortisol, maternal depression, stress, and socio-economic status were also evaluated.

Results. The adjusted association was estimated with multiple linear regression after evaluating confounding through a directed acyclic graph. Median urinary inorganic arsenic in pregnant women was $14.1 \mu \mathrm{g} / \mathrm{L}$ (IQR: 10.4-21.7) while salivary cortisol in the children was $0.17 \mu \mathrm{g} / \mathrm{L}$ (IQR: 0.11-0.38). Among children from the highest income families (> 614 USD/month), arsenic exposure was associated with salivary cortisol. Children in the third quartile of arsenic exposure had -0.769 units of the logarithm of salivary cortiso, compared with those in the first quartile $(p=0.045)$.

Conclusions. In this sample, prenatal exposure to arsenic was associated with salivary cortisol (third quartile of inorganic arsenic), only in infants belonging the highest income strata (> 614 USD). More studies are needed to confirm these preliminary results.
\end{abstract}

\section{Key words}

environmental exposure, arsenic, pregnant women, cohort study, Chile

\section{INTRODUCTION}

Environmental exposure to inorganic arsenic (iAs) through drinking water or consumption of polluted food remains a public health concern for countries with natural arsenic pollution [1]. In fact, iAs leads the priority list proposed by the Agency of Toxic Substances and Disease Register (ATSDR) as a public health issue due to its ubiquity, toxicity, and potential for human exposure [2].

There is strong evidence of an association between high-level iAs exposure and different types of cancer (e.g., bladder, lung, kidney, and skin), cardiovascular diseases, skin lesions, and higher mortality rates compared to the general population [3]. Many countries have implemented water-processing plants, reducing the current exposure levels considerably. However, recent data have suggested that even low-level arsenic exposure is associated with negative health outcomes in adults and children $[4,5,6]$.

Address for correspondence: Macarena Alejandra Valdés Salgado, School of Public Health. Faculty of Medicine. University of Chile, 939 Av. Independencia, 8380453 Santiago, Chile

e-mail: macavaldes@ug.uchile.cl

Received: 07.01.2019; accepted: 20.02.2019; first published: 04.03.2019
Exposure during critical periods, such as gestation, may be considered as an environmental stressor under the Developmental Origins of Health and Disease (DOHaD) paradigm [7]. In mouse models, arsenic exposure causes disruption of early developmental processes with less expression of glucocorticoid receptors (GR) in the hippocampus and hypothalamic-pituitary-adrenal (HPA) axis [4]; consequently, less expression of GR is related to increased corticosterone basal concentration. Mice with higher corticosterone concentration show impairment of spatial-learning and memory functions $[5,6]$. Despite the experimental validity, there is no certainty whether lowlevel arsenic exposure during pregnancy would have the same effects in humans. If that were the case, basal cortisol concentrations would be affected in children exposed during gestation, specifically during the neurodevelopment stage.

Cortisol is the analogous hormone of corticosterone in humans. Cortisol concentrations are influenced by natural circadian rhythms and can be modified by socio-economic status (SES), working conditions, childhood trauma, mental illness, medical treatments, and pathologies $[8,9,10]$. In children, cortisol concentrations correlate with maternal concentration [11]. For most full-term infants, the circadian 
rhythm of cortisol is fully developed after the first year of life [12], implying that age must be taken into account when studying children's cortisol.

\section{OBJECTIVE}

The aim of this study was to explore the association between prenatal iAs exposure and salivary cortisol in a cohort of infants, and compare human findings with experimental evidence studied on mice. Additionally, the modifying effect of SES on the relationship between arsenic and cortisol was examined. The infants in this study were born in Arica, a city in the north of Chile, with a history of natural and anthropogenic arsenic pollution [13]. A recent study showed a broad low-level iAs variability in this area [14], which made the exploration of the effect of arsenic exposure on cortisol feasible.

\section{MATERIALS AND METHOD}

A prospective cohort of pregnant women between their thirteenth and twenty-eighth week of gestation was recruited. The sampling frame was comprised of 591 women who accessed health services in public health centres in Arica, Chile; all women with a singleton pregnancy were invited to participate. In total, 242 women invited to be part of the study accepted, signed an informed consent, completed a sociodemographic and health history questionnaire, and provided a urine sample. The research protocol, questionnaires, and consent forms were reviewed and approved by the Ethical Committee of the Faculty of Medicine of the University of Chile in Santiego (Project No 069-2014).

Each woman was asked to provide a urine sample to assess iAs exposure between June - October 2013. Using pre-labeled urine containers, the samples were collected at their home, stored frozen, and sent to Trace Metals Core Laboratory of Columbia University in New York, USA. Urine iAs was determined by high-performance liquid chromatography with inductively coupled plasma mass spectrometry (HPLCICPMS), separating and quantifying each of the following metabolites: arsenocholine, arsenobetaine, arsenate (AsV), arsenite (AsIII), monomethylarsonic acid (MMA), and dimethylarsinic acid (DMA). Total urinary iAs was considered as the sum of AsV, AsIII, MMA, and DMA. No value was under the limit of detection.

Salivary cortisol collection and analysis in infants. Families were contacted when children were between 18-24 months old; this period was chosen since younger children have greater variability of cortisol concentration [15]. Fieldwork was conducted between July - October 2015. Trained staff took salivary samples from infants and mothers between 09:00-12:00 in a previously scheduled visit. A swab was placed in the child's mouth for 60 seconds and then transported and frozen in a swap storage tube, following the manufacturer's protocol. The same procedure was followed with mothers [16].

Each salivary sample was thawed and centrifuged before analysis. Cortisol concentration was measured using an expanded range high sensitivity salivary cortisol ELISA Salimetric kit. Sample analyses were performed at the
Biotechnology Laboratory of Bernardo O'Higgins at the University of Chile in Santiago, Chile. All samples were analyzed in duplicates.

In a previous pilot study, a test was performed to determine salivary cortisol variability, the reproducibility of the sampling and analytical technique in the same age group. The distribution of salivary cortisol was asymmetric with a median of $0.15 \mu \mathrm{g} / \mathrm{dL}$ (min: 0.073; max: 0.266). Duplicate sampling showed a concordance index (rho) of 0.73 , while duplicate analytical technique reached 0.96 .

Covariates. A theoretical causal framework between arsenic exposure during pregnancy and salivary cortisol in infants was developed based on previous literature (Fig. 1), using the directed acyclic graph (DAG) approach. The potential pathway between prenatal arsenic exposure and salivary cortisol in infants was based on murine models proposed by Martínez and Allan [4, 5, 6]. Reduced expression of glucocorticoid receptor (GR) was demonstrated in mice exposed to arsenic during gestation. Decreased hippocampal GR levels were associated with increased basal plasma corticosterone levels in mice exposed prenatally to arsenic. The same mechanism is proposed for children, expecting a slight increase in basal concentration of cortisol during the neurodevelopment stage. As a negative feedback loop was not reported in mouse offspring, it was also assumed that this physiological mechanism would not be active in children, experiencing smooth increases in cortisol due to gestational exposure to iAs. Additionally, other variables related to cortisol control that could open back-door paths and confound the relationship between the arsenic exposure and cortisol in infants were considered: socio-economic status, having had a stressful pregnancy, mother's depression, and cortisol in mothers.

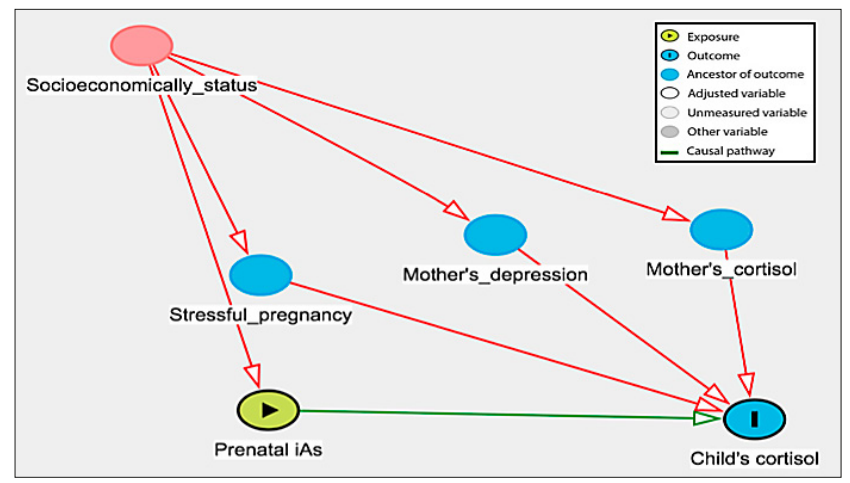

Figure 1. Proposed DAG for the arsenic-cortisol association

Socio-demographic information, such as monthly family income (< 307 USD, 307-614 USD, >614 USD), mother's educational level (years of education), ethnicity (mixed-race, Aymara or other) and occupation (student, homemaker, paid work) were obtained via in-person questionnaires during the first visit. Mothers reported having had a stressful pregnancy (very low or low, moderate, high or very high) and history of depression (medical diagnosis) in a second home visit the year after delivery.

For saliva collection, the time of collection, gender and age of infants, and corticoid use (both the infant and the mother) were registered. Additionally, the $\alpha$-amylase activity $(\mathrm{U} / \mathrm{mL})$ was used to rule-out the autonomic nervous system activation 
due to the sample collection process as a source of stress [17]. a-amylase activity varies between $3.1-423.1 \mathrm{U} / \mathrm{mL}$ in healthy populations, according to the manufacturer (Salimetrics, LLC.).

Statistical analyses. Univariate analyses included central and dispersion measures for continuous variables (median and interquartile range), and frequencies for categorical variables. Bivariate comparison of urinary iAs or salivary cortisol concentration among covariates were performed using nonparametric tests (Mann-Whitney and Kruskal-Wallis test). Given the non-linear relationship between total urinary iAs and salivary cortisol, arsenic exposure was categorized into quartiles, and salivary cortisol was transformed using the natural logarithm.

Multiple linear regression was used to estimate the effect of prenatal arsenic exposure on the cortisol concentration in infants. Maternal cortisol, a stressful pregnancy, and depression were controlled in the multiple regression analyses; these were considered as potential back-door covariates (Fig. 1) $[18,19]$. In addition, the DAG in this study reflected the conceptual framework of the social determinants of health inequalities: poor working conditions, work overload, poor material conditions, and social vulnerability realities [20], which have been linked to changes in the cortisol concentration $[21,22,23]$. In children, a useful proxy for socio-economic status is the monthly family income, which was considered as a potential modifier of the association between arsenic exposure and cortisol concentration.

The goodness of fit of the linear regression model was evaluated considering:

1) multi-collinearity analysis using a variance inflation factor;

2) outlier detection through Cook's distance and leverage against residual squared plot;

3) normality residual analysis using Kernel density plot, Shapiro-Wilk test, and quantile-quantile plots.

A sensitivity analysis was performed to evaluate the robustness of the regression coefficients. Missing data on salivary cortisol $(n=74)$ were ascribed by multiple imputation procedures, and coefficients for linear regression models with and without imputation were contrasted thereafter.

Epidata Entry v3.1 was used to create the database. Data were entered in duplicate to avoid typing errors and conduct quality control checks. Stata IC v12.0 was used for all analyses.

\section{RESULTS}

Between 2013-2015, data collection was completed for 168 infants from the initially enrolled 242 pregnant women. Seventy-four participants dropped-out during the follow-up. Three stillbirths and 30 withdrawals ( 3 refused to continue, 10 moved out of town, and 17 were not available after 3 home visits) occurred during the first year; an additional 41 subjects were lost in the 2 nd year. Baseline characteristics are shown in Table 1.

Urinary iAs in pregnancy. The distribution of total urinary iAs and each arsenical species were asymmetric with a positive bias; the median was $14.1 \mu \mathrm{g} / \mathrm{L}$ (Interquartile Range, IQR: 10.4-21.7). The most prevalent species was DMA. According to the occupational cut-off for arsenic exposure
Table 1. Baseline characteristics of 168 participants, Arica 2013

\begin{tabular}{|c|c|c|}
\hline & $\mathrm{n}(\%)$ & Median (IQR1) \\
\hline Infant Age (months) & & $21(20-23)$ \\
\hline \multicolumn{3}{|l|}{ Infant gender } \\
\hline Female & $85(50.9)$ & \\
\hline Male & $82(49.1)$ & \\
\hline Gestational age (weeks) & & $39(39-40)$ \\
\hline Maternal age (years) & & $25(21-30)$ \\
\hline Maternal education (years of total education) & & $12(12-14)$ \\
\hline \multicolumn{3}{|l|}{ Maternal Ethnicity } \\
\hline Mixed-raced & $113(67.7)$ & \\
\hline Aymara & $47(28.1)$ & \\
\hline Other & $7(4.2)$ & \\
\hline \multicolumn{3}{|l|}{ Monthly family Income } \\
\hline$<307$ USD & $63(38.2)$ & \\
\hline $307-614$ USD & $70(42.4)$ & \\
\hline$>614$ USD & $32(19.4)$ & \\
\hline \multicolumn{3}{|l|}{ Maternal Occupation } \\
\hline Student & $40(25.0)$ & \\
\hline Housewife & $76(47.5)$ & \\
\hline Remunerated job & $44(27.5)$ & \\
\hline \multicolumn{3}{|l|}{ Stressful pregnancy } \\
\hline Very low or low & $54(33.1)$ & \\
\hline Moderate & $84(51.5)$ & \\
\hline High or very high & $25(15.4)$ & \\
\hline \multicolumn{3}{|l|}{ Maternal depression diagnosed by medical doctor } \\
\hline Yes & $37(22.7)$ & \\
\hline No & $126(77.3)$ & \\
\hline
\end{tabular}

${ }^{1}$ Interquartile Range: Centile 25 - Centile 75.

[13], 14 samples $(8.3 \%)$ were above $35 \mu \mathrm{g} / \mathrm{L}$. Infant gender $(\mathrm{p}=0.140)$, mother's education level $(\mathrm{P}=0.960)$, and cortisol in mothers $(\mathrm{P}=0.732)$ were independent of urinary iAs. Family income, occupation, ethnicity, stressful pregnancy, and maternal depression were not associated with urinary iAs concentration (Tab. 2).

Salivary cortisol in infants. Salivary cortisol distribution was skewed with a positive bias. The median was $0.17 \mu \mathrm{g} / \mathrm{dL}$ (IQR: 0.11-0.38) with minimum and maximum values of $0.0096 \mu \mathrm{g} / \mathrm{dL}$ and $1.3 \mu \mathrm{g} / \mathrm{dL}$, respectively. $\alpha$-amylase activity, a biomarker for acute stress in infants, and educational level in mothers were independent of cortisol concentration ( $\mathrm{P}=0.196$ and $\mathrm{P}=0.683$, respectively). There were no differences between males and females regarding cortisol concentration $(\mathrm{P}=0.572)$.

Maternal cortisol concentration (used as a biomarker for stress) was linearly correlated with cortisol concentrations in infants $(r=0.791 ; \mathrm{P}<0.0001)$. Family income, ethnicity, occupation, stressful pregnancy, and diagnosed depression were not associated with salivary cortisol (Tab. 3).

Association between urinary iAs and salivary cortisol in infants. In multiple linear regression analyses, the relationship between urinary iAs and salivary cortisol varied according to family income (Tab. 3). In infants belonging to the $<307$ USD family income stratum and between 307-614 
Table 2. Urinary iAs concentration in 168 pregnant women (Arica, 2013) and salivary cortisol concentration in 168 infants (Arica, 2015) by covariates

\begin{tabular}{lcccc}
\hline Covariates & $\begin{array}{c}\text { iAs } \boldsymbol{\mu g} / \mathbf{L} \\
\text { Median (IQR })\end{array}$ & $\boldsymbol{P}$ & $\begin{array}{c}\text { Cortisol } \boldsymbol{\mu g} / \mathbf{d L} \\
\text { Median (IQR })\end{array}$ & $\boldsymbol{P}$ \\
\hline Monthly family Income & & & & \\
\hline$<307$ USD & $14.6(10.4-21.7)$ & 0.923 & $0.174(0.121-0.392)$ & 0.515 \\
\hline $307-614$ USD & $14.0(10.5-23.0)$ & $0.145(0.098-0.365)$ & \\
\hline$>$ 614 USD & $14.4(11.5-20.8)$ & $0.196(0.117-0.402)$ & \\
\hline Ethnicity & & & & \\
\hline Mixed-race & $13.8(10.4-20.9)$ & 0.395 & $0.179(0.115-0.382)$ & 0.240 \\
\hline Aymara & $15.4(11.1-22.6)$ & $0.170(0.104-0.408)$ & \\
\hline Other & $18.3(9.3-28.3)$ & $0.127(0.104-0.150)$ & \\
\hline Occupation & & & & \\
\hline Student & $14.2(10.0-21.7)$ & 0.755 & $0.181(0.111-0.439)$ & 0.743 \\
\hline Housewife & $13.9(11.8-20.8)$ & & $0.165(0.092-0.426)$ & \\
\hline Remunerated job & $15.0(10.5-23.0)$ & $0.167(0.118-0.329)$ & \\
\hline Stressful pregnancy & & & & \\
\hline Very low or low & $14.5(10.4-25.5)$ & 0.955 & $0.165(0.113-0.320)$ & 0.219 \\
\hline Moderate & $14.6(10.5-20.2)$ & $0.247(0.111-0.641)$ & \\
\hline High or very high & $12.8(10.0-16.0)$ & $0.156(0.102-0.248)$ & \\
\hline $\begin{array}{l}\text { Depression diagnosed by } \\
\text { medical doctor }\end{array}$ & $14.7(10.8-26.2)$ & 0.452 & $0.172(0.124-0.382)$ & 0.383 \\
\hline Yes & $14.1(10.0-21.0)$ & $0.164(0.110-0.337)$ & \\
\hline No & & & & \\
\hline & & & & \\
\hline
\end{tabular}

'Interquartile Range: Centile 25 - Centile 75.

USD family income stratum, urinary iAs was not associated with salivary cortisol. Three outliers were detected using Cook's distance and leverage against the residual squared plot. Infants belonging to family income strata $>614$ USD and exposed to a concentration between $14.08-21.70 \mu \mathrm{g} / \mathrm{L}$ of iAs had $-0.769 \mu \mathrm{g} / \mathrm{dL}$ of the natural logarithm of salivary cortisol than those exposed to $2.05-10.43 \mu \mathrm{g} / \mathrm{L}$ of iAs during pregnancy $(\mathrm{P}=0.045)$

In addition, the 3 stratified models showed a strong association between the natural logarithm of salivary cortisol in infants and salivary cortisol in mothers $(\mathrm{P}<0.001)$. The models for each family income strata did not show multicollinearity according to the variance inflation factor; residual means were close to zero, and residual distributions did not reject normality.

Sensitivity analyses. Regarding the 74 non-participants, the median urinary iAs concentration was slightly higher than that of the participants. The distributions of covariates which included years of education, ethnicity, family income, occupation, stressful pregnancy, diagnosed depression, child's gender, gestational age, and mother's age, were similar between participants and non-participants (Tab. 4). The results obtained in the stratified models with imputed data were consistent with the results without imputations (Tab. 5).

\section{DISCUSSION}

An association was observed between the $3^{\text {rd }}$ quartile of iAs concentration and the natural logarithm of salivary cortisol in infants belonging to the $>614$ USD income stratum. The
Table 3. Association between urinary iAs concentration and natural logarithm of salivary cortisol concentration, adjusted by covariable in each stratum of family income, Arica 2015

\begin{tabular}{|c|c|c|c|c|}
\hline & Coef. & \multicolumn{2}{|c|}{$95 \% \mathrm{Cl}$} & $P$ \\
\hline \multicolumn{5}{|c|}{ Monthly family income < 307 USD } \\
\hline \multicolumn{5}{|l|}{ iAs quartile } \\
\hline $2.05-10.43 \mu \mathrm{g} / \mathrm{L}$ & Ref. & & & \\
\hline$>10.43-14.08 \mu \mathrm{g} / \mathrm{L}$ & -0.178 & -0.584 & 0.228 & 0.383 \\
\hline$>14.08-21.70 \mu \mathrm{g} / \mathrm{L}$ & -0.094 & -0.464 & 0.277 & 0.614 \\
\hline$>21.70-69.3 \mu \mathrm{g} / \mathrm{L}$ & 0.271 & -0.131 & 0.672 & 0.182 \\
\hline \multicolumn{5}{|c|}{ Depression diagnosed by medical doctor } \\
\hline No & Ref. & & & \\
\hline Yes & 0.086 & -0.271 & 0.443 & 0.629 \\
\hline \multicolumn{5}{|l|}{ Stressful pregnancy } \\
\hline Very low or low & Ref. & & & \\
\hline Moderate & 0.009 & -0.318 & 0.336 & 0.955 \\
\hline High or very high & 0.010 & -0.471 & 0.492 & 0.965 \\
\hline Maternal cortisol ( $\mu \mathrm{g} / \mathrm{dL})$ & 2.246 & 1.774 & 2.718 & $<0.001$ \\
\hline \multicolumn{5}{|c|}{ Monthly family income 307 - 614 USD } \\
\hline \multicolumn{5}{|l|}{ iAs quartile } \\
\hline $2.05-10.43 \mu \mathrm{g} / \mathrm{L}$ & Ref. & & & \\
\hline$>10.43-14.08 \mu \mathrm{g} / \mathrm{L}$ & 0.111 & -0.416 & 0.637 & 0.676 \\
\hline$>14.08-21.70 \mu \mathrm{g} / \mathrm{L}$ & 0.013 & -0.585 & 0.559 & 0.964 \\
\hline$>21.70-69.3 \mu \mathrm{g} / \mathrm{L}$ & 0.137 & -0.399 & 0.672 & 0.611 \\
\hline \multicolumn{5}{|c|}{ Depression diagnosed by medical doctor } \\
\hline No & Ref. & & & \\
\hline Yes & -0.005 & -0.430 & 0.419 & 0.980 \\
\hline \multicolumn{5}{|l|}{ Stressful pregnancy } \\
\hline Very low or low & Ref. & & & \\
\hline Moderate & -0.358 & -0.789 & 0.072 & 0.101 \\
\hline High or very high & -0.180 & -0.762 & 0.401 & 0.537 \\
\hline Maternal cortisol ( $\mu \mathrm{g} / \mathrm{dL})$ & 1.968 & 1.363 & 2.573 & $<0.001$ \\
\hline
\end{tabular}

\section{iAs quartile}

$2.05-10.43 \mu \mathrm{g} / \mathrm{L}$ Ref.

$>10.43-14.08 \mu \mathrm{g} / \mathrm{L}$

$\begin{array}{llll}-0.052 & -0.809 & 0.705 & 0.889\end{array}$

$>14.08-21.70 \mu \mathrm{g} / \mathrm{L}$

$\begin{array}{llll}-0.769 & -1.538 & -0.001 & 0.045\end{array}$

$>21.70-69.3 \mu \mathrm{g} / \mathrm{L}$

$\begin{array}{rrrr}-0.232 & -0.641 & 1.107 & 0.587\end{array}$

Depression diagnosed by medical doctor

\begin{tabular}{lllll}
\hline No & Ref. & & & \\
\hline Yes & -0.435 & -1.274 & 0.403 & 0.294
\end{tabular}

Stressful pregnancy

Very low or low Ref.

\begin{tabular}{lllll}
\hline Moderate & -0.010 & -0.695 & 0.674 & 0.975
\end{tabular}

High or very high

$\begin{array}{llll}0.090 & -0.639 & 0.820 & 0.800\end{array}$

Maternal cortisol $(\mu \mathrm{g} / \mathrm{dL})$

$\begin{array}{llll}1.873 & 1.007 & 2.739 & <0.001\end{array}$

median concentration of urinary iAs in pregnant women was $14.1 \mu \mathrm{g} / \mathrm{L}$ (min: 2.05; $\max : 69.3$ ), while the median salivary cortisol concentration in infants was $0.17 \mu \mathrm{g} / \mathrm{dL}$ (min: $0.0096 \mu \mathrm{g} / \mathrm{dL}$; max: $1.3 \mu \mathrm{g} / \mathrm{dL}$ ).

The median of urinary iAs reported in this study was low, which is consistent with similar studies that have explored the effects of intrauterine exposure to low concentrations of 
Table 4. Characteristics of non-participants

\begin{tabular}{lc}
\hline Covariates & Non participants $(\mathrm{n}=74)$ \\
\hline Total urinary iAs $\mu \mathrm{g} / \mathrm{L}$ (Median; IQR) & $16.3 ; 12.1$ \\
\hline Years of education (Median; IQR) & $12 ; 1$ \\
\hline Ethnicity (\% Mixed-race) & 60.0 \\
\hline Monthly family income (\% <307 USD) & 47.2 \\
\hline Occupation (\% Housewife) & 54.7 \\
\hline Stressful pregnancy (\%) & 81.8 \\
\hline Depression diagnosed by medical doctor (\%) & 18.2 \\
\hline Gender (\% women) & 47.3 \\
\hline Gestational age in weeks (Median; IQR) & $39 ; 2$ \\
\hline Mother's age (Median; IQR) & $26 ; 8$
\end{tabular}

arsenic. Davis et al. [24] reported a median of $3.1 \mu \mathrm{g} / \mathrm{L}$ with a range from $0.0-22.0 \mu \mathrm{g} / \mathrm{L}$, and excluded organic arsenical species from the analysis to evaluate the effect of arsenic exposure during pregnancy and foetal growth.

Murine models have shown that exposure to $10 \mu \mathrm{g} / \mathrm{L}$ of iAs through water consumption during and after pregnancy causes adverse health effects in mothers and their offspring, especially with respect to neurodevelopment and adaptation to stress conditions [25]. In humans, prenatal As exposure has been associated with global DNA methylation in cord blood DNA, which suggests a potential mechanism of early-life As exposure and health outcomes later in life [26, 27].

Total urinary iAs concentration was used as a proxy for exposure, based on the assumptions that this measurement is correlated with intrauterine exposure [28, 29,30], and that the exposure is steady throughout pregnancy. The latter assumption is supported by official records of heavy metal content of drinking water which show that arsenic levels in drinking water did not vary during the 2013-2015 period [31].

The range of salivary cortisol in children (0.034$0.645 \mu \mathrm{g} / \mathrm{dL}$ ) were wider than the values suggested by the manufacturer [32]. The sample in the current study differed from the sample used for reference values whose ages ranged from $2.5-5.5$ years. According to a study by Watamura, the hypothalamus-pituitary-adrenal axis maturation develops even after the third year [33]. Age-dependency was confirmed in another study showing that younger children had higher basal cortisol concentrations [15]. In the presented study, cortisol differences by age were not significant, and were likely related to the age homogeneity of the sample.

To further study the effect of total urinary iAs in pregnancy, the sample in the current study was stratified into quartiles of monthly family income. The association between the third quartile of urinary iAs (reference group: first quartile) and the natural logarithm of salivary cortisol in infants, occurred at low concentrations of exposure (>14.08-21.70 $\mu \mathrm{g} / \mathrm{L})$, and only in the group of infants belonging the $>614$ USD income stratum. Specifically, arsenic exposure did not explain cortisol variability by itself, but depended on family income.

It is suggest that the variability of cortisol concentration in infants of lower income strata (monthly family income $<614$ USD) may be explained by the cortisol level in mothers and other detrimental unmeasured variables, such as violence, psychological adversities, traumatic experiences, or adverse working conditions $[34,35,36]$. On the other hand, in infants from higher-income families (monthly family income $>614$ USD), the variability of cortisol concentration was also
Table 5. Coefficients of multiple regression including imputed data

\begin{tabular}{lcccc}
\hline \multicolumn{1}{l}{ Coef. } & $95 \% \mathrm{Cl}$ & $\mathrm{P}$ \\
\hline Monthly family income $<307$ USD & & & & \\
\hline iAs quartile & & & & \\
\hline $2.05-10.43 \mathrm{\mu g} / \mathrm{L}$ & Ref. & & & \\
\hline$>10.43-14.08 \mu \mathrm{g} / \mathrm{L}$ & -0.167 & -0.519 & 0.186 & 0.350 \\
\hline$>14.08-21.70 \mu \mathrm{g} / \mathrm{L}$ & -0.068 & -0.386 & 0.250 & 0.672 \\
\hline$>21.70-69.3 \mu \mathrm{g} / \mathrm{L}$ & 0.120 & -0.221 & 0.461 & 0.485 \\
\hline Depression diagnosed by medical doctor & & & & \\
\hline No & Ref. & & & \\
\hline Yes & -0.021 & -0.347 & 0.304 & 0.898 \\
\hline Stressful pregnancy & & & & \\
\hline Very low or low & Ref. & & & \\
\hline Moderate & -0.019 & -0.315 & 0.277 & 0.897 \\
\hline High or very high & 0.108 & -0.262 & 0.477 & 0.564 \\
\hline Maternal cortisol $(\boldsymbol{\mu g} / \mathrm{dL})$ & $\mathbf{2 . 2 2 9}$ & $\mathbf{1 . 7 9 8}$ & $\mathbf{2 . 6 5 9}$ & $<\mathbf{0 . 0 0 1}$ \\
\hline Monty famiy & & & &
\end{tabular}

Monthly family income $307-614$ USD

iAs quartile

\begin{tabular}{lcccc}
\hline $2.05-10.43 \mu \mathrm{g} / \mathrm{L}$ & Ref. & & & \\
\hline$>10.43-14.08 \mu \mathrm{g} / \mathrm{L}$ & 0.108 & -0.322 & 0.539 & 0.619 \\
\hline$>14.08-21.70 \mu \mathrm{g} / \mathrm{L}$ & 0.014 & -0.428 & 0.456 & 0.951 \\
\hline$>21.70-69.3 \mu \mathrm{g} / \mathrm{L}$ & 0.072 & -0.366 & 0.510 & 0.745 \\
\hline
\end{tabular}

Depression diagnosed by medical doctor

\begin{tabular}{lcllll}
\hline No & Ref. & & & \\
\hline Yes & 0.015 & -0.314 & 0.344 & 0.928 \\
\hline
\end{tabular}

Stressful pregnancy

\begin{tabular}{lcccc}
\hline Very low or low & Ref. & & & \\
\hline Moderate & -0.224 & -0.567 & 0.120 & 0.199 \\
\hline High or very high & -0.157 & -0.643 & 0.329 & 0.523 \\
\hline Maternal cortisol $(\boldsymbol{\mu g} / \mathbf{d L})$ & $\mathbf{1 . 8 6 3}$ & $\mathbf{1 . 3 4 1}$ & $\mathbf{2 . 3 8 5}$ & $<\mathbf{0 . 0 0 1}$ \\
\hline
\end{tabular}

Monthly family income > 614 USD

iAs quartile

\begin{tabular}{lcccc}
\hline $2.05-10.43 \mu \mathrm{g} / \mathrm{L}$ & Ref. & & & \\
\hline$>10.43-14.08 \mu \mathrm{g} / \mathrm{L}$ & -0.159 & -0.766 & 0.446 & 0.596 \\
\hline$>\mathbf{1 4 . 0 8}-\mathbf{2 1 . 7 0} \mathbf{\mu g} / \mathbf{L}$ & $\mathbf{- 0 . 6 0 1}$ & $\mathbf{- 1 . 1 6 9}$ & $\mathbf{- 0 . 0 3 3}$ & $\mathbf{0 . 0 3 9}$ \\
\hline$>21.70-69.3 \mu \mathrm{g} / \mathrm{L}$ & -0.050 & -0.714 & 0.613 & 0.878 \\
\hline Depression diagnosed by medical doctor & & & & \\
\hline No & Ref. & & & \\
\hline Yes & -0.509 & -1.244 & 0.225 & 0.168 \\
\hline Stressful pregnancy & & & & \\
\hline Very low or low & Ref. & & & \\
\hline Moderate & -0.183 & -0.685 & 0.319 & 0.464 \\
\hline High or very high & 0.054 & -0.531 & 0.693 & 0.853 \\
\hline Maternal cortisol $(\boldsymbol{\mu g} / \mathbf{d L})$ & $\mathbf{1 . 7 0 5}$ & $\mathbf{0 . 9 7 8}$ & $\mathbf{2 . 4 3 2}$ & $<\mathbf{0 . 0 0 1}$ \\
\hline
\end{tabular}

related to mothers' cortisol levels, but environmental factors such as the exposure to arsenic may become influential, i.e. environmental pollutants, such as arsenic, could explain the cortisol variability under special conditions when the individuals are not exposed to traumatic experiences or adverse conditions.

In the presented sample, monthly family income was neither associated with the iAs concentration nor with salivary cortisol. Interestingly, when exploring the association 
of family income with other maternal outcomes, such as gestational diabetes, preeclampsia, low birth weight, preterm birth, postpartum depression, and mothers' diagnosed depression, it was noticed that those with lower income (monthly family income <614 USD) had a higher prevalence of diagnosed depression (data not shown). This association could be a potential pathway that links socio-economic status with cortisol concentration in infants. Thus, mediators as mother health status - especially, mental health - should be considered in future research.

No association was found between cortisol concentrations in children or mothers who had had a stressful pregnancy. Nevertheless, the questions regarding stressful situations were based on self-perception and conceivable expectations, rather than objective facts, which may have led to an inflated frequency, hence biasing the association.

According to the literature, social stressors seem to be powerful factors that explain the variability of cortisol concentrations, [37]. Even with strong evidence of the effect of arsenic over corticosterone in experimental studies, replicating the same results in humans might be difficult considering unmeasured social factors. Based on mouse models, cortisol concentration might be higher in infants exposed to higher concentration of iAs, presumably exposed through drinking water during gestation; however, in the presented study it was not possible to estimate the influence of unmeasured traumatic experiences in the sample.

Strengths and limitations of the study. Sensitivity analysis showed the robustness of the obtained regression coefficients. Despite missing data on salivary cortisol, the association estimated on the stratified models were found in data without imputation (Tab. 3) and with imputation (Tab. 5). The characteristics of non-participants were similar to the characteristics of the obtained sample (Tab. 4), and although a selection bias due to losses during the follow-up was one of the limitations in this study, our missingness seemed to be random.

The DAG approach is one of the strengths of this study, which considers the causal network underlying the effect of arsenic on salivary cortisol. Using this approach, response to two aims was achieved: to incorporate the evidence based on mouse models, which gave biological plausibility to the authors' research question, and to develop an analytical strategy that recognizes confounding and mediating pathways and prevents over-fitting and selection bias [38]. The consideration of variables, such as cortisol in mothers, mother's depression, stress during pregnancy, and socio-economic status, was supported by the review of literature [18, 19, 21, 39].

The second strength on this study was the use of a data collection and measurement technique that is highly reproducible, implying that the results are reliable in the preanalytical and analytical phases. Both exposure and outcome variables were measured on continuous scales using highprecision analytical techniques, avoiding misclassification bias in the two main variables of this study.

There is no reference range for salivary cortisol concentration for infants, and few studies have assessed it longitudinally $[12,40]$. In a cohort of Swedish infants, serum and salivary cortisol concentrations were assessed from birth to 12 months old. The results showed that variability of salivary cortisol concentrations increased each month, and achieved the higher variance at five months old (min: $0.1015 \mu \mathrm{g} / \mathrm{dL}$; max: $23.59 \mu \mathrm{g} /$
dL). Furthermore, in an Argentinian cohort of newborns, serum and salivary cortisol levels were measured at birth and one month later. The authors noted a higher variability of values at birth, which decreased one-month later. Prior to the presented study, a pilot study was undertaken to calibrate the analytical technique and to explore the salivary cortisol concentration in a similar population. However, there is no assurance that the results obtained are conclusive regarding the cortisol range.

As previously noted, the dropouts that occurred during the follow-up represent a limitation of this study. Although sensitivity analysis with imputed data did not show important differences from the results with complete cases, the obtained results could be more accurate with a complete data set. With the presented sample size, the estimated error for the multiple linear regression coefficient was 0.113 , assuming $80 \%$ of confidence.

One potential bias in this study was the information bias. Information for some variables, such as stressful pregnancies, was collected through self-reported questionnaire, and therefore susceptible to own perception or previous experiences. The pilot study attempted to minimize this research bias.

Socio-economic status was a latent variable in this study, but family income was used as a proxy, which could have introduced a misclassification bias. Moreover, the sample had little variability with respect to income. Future studies may consider taking a structural equation modeling approach [41], considering ethnicity, education, occupation, and income as factors behind the socio-economic status construct, and compare results with the current study. These variables are included in the conceptual framework for action on the social determinants of health to challenge health inequities [20].

\section{CONCLUSIONS}

This is the first study estimating the association between prenatal concentrations of iAs as a proxy of intrauterine exposure and concentrations of cortisol, as a biomarker of prenatal effect of arsenic exposure in infants aged 18-24 months. In this sample of infants, whose mothers attended public health centres, prenatal exposure to arsenic was associated with salivary cortisol (third quartile of iAs), only in infants belonging the highest income strata (> 614 USD). More studies are needed to confirm these preliminary results.

Although the level of exposure to iAs in this cohort was low, current evidence verifies the importance of studying the effects of exposure to low concentrations during critical periods of development. In humans, it is necessary to investigate the effects of low concentrations of arsenic, as well as other pollutants, during prenatal life and early childhood, given the impact of these exposures on medium and longterm health outcomes. The study of biomarkers, such as cortisol, is a fundamental area of environmental research given its contribution to our understanding of disease pathways, and the identification of vulnerable subgroups.

\section{REFERENCES}

1. Cantor KP, Lubin JH. Arsenic, internal cancers, and issues in inference from studies of low-level exposures in human populations. Toxicol Appl Pharmacol 2007; 222 (3): 252-257. 10.1016/j.taap.2007.01.026 
2. Agency for Toxic Substaces and Disease Registry. The Priority List of Hazardous Substances That Will Be the Candidates for Toxicological Profiles. Available online: www.atsdr.cdc.gov/spl/resources/ atsdr_2015_spl_support_document.pdf. (Accessed on 03.10.2016).

3. Yunus M, Sohel N, Hore SK, Rahman M. Arsenic exposure and adverse health effects: a review of recent findings from arsenic and health studies in Matlab, Bangladesh. Kaohsiung J Med Sci. 2011; 27(9): 371-376. 10.1016/j.kjms.2011.05.012

4. Martinez-Finley EJ, Goggin SL, Labrecque MT, Allan AM. Reduced expression of MAPK/ERK genes in perinatal arsenic-exposed offspring induced by glucocorticoid receptor deficits. Neurotoxicol Teratol. 2011; 33(5): 530-537. 10.1016/j.ntt.2011.07.003

5. Martinez EJ, Kolb BL, Bell A, Savage DD, Allan AM. Moderate perinatal arsenic exposure alters neuroendocrine markers associated with depression and increases depressive-like behaviors in adult mouse offspring. Neurotoxicology 2008; 29(4): 647-655. 10.1016/j.neuro.2008.05.004

6. Martinez-Finley EJ, Ali AM, Allan AM. Learning deficits in C57BL/6J mice following perinatal arsenic exposure: consequence of lower corticosterone receptor levels? Pharmacol Biochem Behav. 2009; 94(2): 271-277. 10.1016/j.pbb.2009.09.006

7. Grandjean P, Barouki R, Bellinger DC, Casteleyn L, Chadwick LH, Cordier S, et al. Life-Long Implications of Developmental Exposure to Environmental Stressors: New Perspectives. Endocrinology 2015; 156(10): 3408-3415. 10.1210/EN.2015-1350

8. Holleman M, Vreeburg SA, Dekker JJ, Penninx BW. The relationships of working conditions, recent stressors and childhood trauma with salivary cortisol levels. Psychoneuroendocrinology 2012; 37(6): 801809. 10.1016/j.psyneuen.2011.09.012

9. Schreuder MM, Vinkers CH, Mesman E, Claes S, Nolen WA, Hillegers $\mathrm{MH}$. Childhood trauma and HPA axis functionality in offspring of bipolar parents. Psychoneuroendocrinology 2016; 74: 316-323. 10.1016/j.psyneuen.2016.09.017

10. Ursache A, Noble KG, Blair C. Socioeconomic Status, Subjective Social Status, and Perceived Stress: Associations with Stress Physiology and Executive Functioning. Behav Med. 2015; 41(3): 145-154. 10.1080/08964289.2015.1024604

11. Tarullo AR, St John AM, Meyer JS. Chronic stress in the mother-infant dyad: Maternal hair cortisol, infant salivary cortisol and interactional synchrony. Infant Behav Dev. 2017; 47: 92-102. 10.1016/j.infbeh.2017.03.007

12. Ivars K, Nelson N, Theodorsson A, Theodorsson E, Strom JO, Morelius E. Development of Salivary Cortisol Circadian Rhythm and Reference Intervals in Full-Term Infants. PLoS One 2015; 10(6): e0129502. 10.1371/ journal.pone.0129502

13. Biblioteca del Congreso Nacional de Chile. Historia de la Ley No20590. Establece un programa de intervención en zonas con presencia de polimetales en la comuna de Arica. Available online: https://www.bcn. $\mathrm{cl} /$ historiadelaley/nc/historia-de-la-ley/4436/ (Accessed on 03.10.2016).

14. Burgos S, Tenorio M, Zapata P, Cáceres D, Klarian J, Alvarez N, et al. Cognitive Performance Among Cohorts Of Children Exposed To A Waste Disposal Site Containing Lead in Chile. Int J Environ Health Res. $2017 ; 27(2)$ : 117-125.

15. Tamayo YOM, Tellez-Rojo MM, Wright RJ, Coull BA, Wright RO. Longitudinal associations of age and prenatal lead exposure on cortisol secretion of 12-24 month-old infants from Mexico City. Environ Health 2016; 15: 41. 10.1186/s12940-016-0124-1

16. Salimetrics USA, Expanded Range High Sensitivity Salivary Cortisol. Enzyme Immunoassay Kit Protocol. Available online: www.salimetrics. com/assets/documents/1-3002n.pdf. (Accessed on 27.10.2016).

17. Nater UM, Rohleder N. Salivary alpha-amylase as a non-invasive biomarker for the sympathetic nervous system: current state of research. Psychoneuroendocrinology 2009; 34(4): 486-496. 10.1016/j. psyneuen.2009.01.014

18. Saxbe DE, Margolin G, Spies Shapiro L, Ramos M, Rodriguez A, Iturralde E. Relative influences: patterns of HPA axis concordance during triadic family interaction. Health Psychol. 2014; 33(3): 273-281. 10.1037/a0033509

19. Karlen J, Frostell A, Theodorsson E, Faresjo T, Ludvigsson J. Maternal Influence on Child HPA Axis: A Prospective Study of Cortisol Levels in Hair. Pediatrics 2013; 132(5): e1333-e1340. 10.1542/peds.2013-1178

20. Solar O, Irwin A. A conceptual framework for action on the social determinants of health. Social Determinants of Health Discussion Paper 2 (Policy and Practice). 2010.

21. Kumari M, Badrick E, Chandola T, Adler NE, Epel E, Seeman T, et al. Measures of social position and cortisol secretion in an aging population: findings from the Whitehall II study. Psychosom Med. 2010; 72(1): 27-34. 10.1097/PSY.0b013e3181c85712
22. Kumari M, Badrick E, Ferrie J, Perski A, Marmot M, Chandola T. Self-reported sleep duration and sleep disturbance are independently associated with cortisol secretion in the Whitehall II study. J Clin Endocrinol Metab. 2009; 94(12): 4801-4809. 10.1210/jc.2009-0555

23. Kumari M, Badrick E, Chandola T, Adam EK, Stafford M, Marmot MG, et al. Cortisol secretion and fatigue: associations in a community based cohort. Psychoneuroendocrinology 2009; 34(10): 1476-1485. 10.1016/j. psyneuen.2009.05.001

24. Davis MA, Higgins J, Li Z, Gilbert-Diamond D, Baker ER, Das A, et al. Preliminary analysis of in utero low-level arsenic exposure and fetal growth using biometric measurements extracted from fetal ultrasound reports. Environ Health 2015; 14: 12. 10.1186/1476-069X-14-12

25. Kozul-Horvath CD, Zandbergen F, Jackson BP, Enelow RI, Hamilton JW. Effects of low-dose drinking water arsenic on mouse fetal and postnatal growth and development. PLoS One 2012; 7(5): e38249. 10.1371/journal.pone.0038249

26. Pilsner JR, Hall MN, Liu X, Ilievski V, Slavkovich V, Levy D, et al. Influence of prenatal arsenic exposure and newborn sex on global methylation of cord blood DNA. PLoS One 2012; 7(5): e37147.

27. Kile ML, Baccarelli A, Hoffman E, Tarantini L, Quamruzzaman Q, Rahman M, et al. Prenatal arsenic exposure and DNA methylation in maternal and umbilical cord blood leukocytes. Environ Health Perspect. 2012; 120(7): 1061-1066.

28. Concha G, Vogler G, Lezcano D, Nermell B, Vahter M. Exposure to inorganic arsenic metabolites during early human development. Toxicological Sci. 1998; 44(2): 185-190. 10.1093/toxsci/44.2.185

29. National Research Council (US) Subcommittee on Arsenic in Drinking Water. Arsenic in Drinking Water. Washington (DC): National Academies Press (US); 1999. 6, Biomarkers of Arsenic Exposure. Available online: https://www.ncbi.nlm.nih.gov/books/NBK230898/ (Accessed on 27.10.2016).

30. Kile Molly L, Hoffman E, Hsueh Y-M, Afroz S, Quamruzzaman Q, Rahman M, et al. Variability in Biomarkers of Arsenic Exposure and Metabolism in Adults over Time. Environ Health Perspectives 2009; 117(3): 455-460. 10.1289/ehp.11251

31. Superintendencia de Servicios Sanitarios. Gobierno de Chile. Fiscalización de empresas sanitarias. Calidad del agua potable. 2013. Available online: http://www.siss.gob.cl/586/w3-propertyvalue-6403. html\#calidad (Accessed on 27.10.2016).

32. Aardal E, Holm AC. Cortisol in saliva--reference ranges and relation to cortisol in serum. (0939-4974 (Print)),

33. Watamura SE, Donzella B, Kertes DA, Gunnar MR. Developmental changes in baseline cortisol activity in early childhood: relations with napping and effortful control. Dev Psychobiol. 2004; 45(3): 125-133. $10.1002 /$ dev.20026

34. Cerda-Molina AL, Borráz-León JI, Mayagoitia-Novales L, Gaspar Del Río AT. Reactividad del cortisol y salud mental en adultos expuestos a violencia temprana: revisión sistemática. Revista Panamericana de Salud Pública 2017; 1-9. 10.26633/rpsp.2017.171

35. Cordero MI, Moser DA, Manini A, Suardi F, Sancho-Rossignol A, Torrisi R, et al. Effects of interpersonal violence-related post-traumatic stress disorder (PTSD) on mother and child diurnal cortisol rhythm and cortisol reactivity to a laboratory stressor involving separation. Horm Behav. 2017; 90:15-24. 10.1016/j.yhbeh.2017.02.007

36. Bair-Merritt MH, Voegtline K, Ghazarian SR, Granger DA, Blair C, Family Life Project I, et al. Maternal intimate partner violence exposure, child cortisol reactivity and child asthma. Child Abuse Negl. 2015; 48 : 50-57. 10.1016/j.chiabu.2014.11.003

37. Gunnar MR, Donzella B. Social regulation of the cortisol levels in early human development. Psychoneuroendocrinology 2002; 27: 199-220.

38. Howards PP, Schisterman EF, Heagerty PJ. Potential Confounding by Exposure History and Prior Outcomes. Epidemiology 2007; 18(5): 544-551. 10.1097/EDE.0b013e31812001e6

39. Chandola T, Rouxel P, Marmot MG, Kumari M. Retirement and Socioeconomic Differences in Diurnal Cortisol: Longitudinal Evidence From a Cohort of British Civil Servants. J Gerontol B Psychol Sci Soc Sci. 2017; 10.1093/geronb/gbx058

40. Forclaz MV, Moratto E, Pennisi A, Falco S, Olsen G, Rodriguez P, et al. Salivary and serum cortisol levels in newborn infants. Arch Argent Pediatr. 2017; 115(3): 262-266. 10.5546/aap.2017.eng.262

41. Sánchez BN, Budtz-Jørgensen E, Ryan LM, Hu H. Structural Equation Models. J Am Statistical Assoc. 2005; 100(472): 1443-1455. 10.1198/016214505000001005

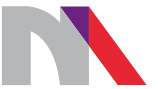

Ministry of Science and Higher Education

Republic of Poland

Generation of the DOI (Digital Object Identifier) - task financed under the agreement No. 618/P-DUN/2019 by the Minister of Science and Higher Education 